\title{
Noninvasive Positive Pressure Ventilation in Patients with Acute Respiratory Failure Secondary to Acute Exacerbation of Chronic Obstructive Pulmonary Disease
}

\author{
Sheeba F. Ansari ${ }^{1}$, Mubeen Memon ${ }^{2}$, Naveed Brohi ${ }^{3}$, Amber Tahir ${ }^{4}$ \\ 1. Internal Medicine, Liaquat University of Medical and Health Sciences, Jamshoro, PAK 2. Pulmonology, Civil Hospital, \\ Jamshoro, PAK 3. Pulmonology, Jinnah Postgraduate Medical Centre Hospital, Karachi, PAK 4. Internal Medicine, Dow \\ University of Health Sciences, Karachi, PAK
}

Corresponding author: Amber Tahir, siddiquiambertahir@gmail.com

\section{Abstract \\ Introduction}

Acute exacerbation of chronic obstructive pulmonary disease (AECOPD) is a leading cause of poor quality of life and mortality in developing countries. Noninvasive positive pressure ventilation (NIPPV) remains the first-line intervention in hospitalized patients with acute respiratory failure (ARF) due to AECOPD. However, NIPPV may fail in some patients. This study was conducted to assess the frequency of NIPPV failure and clinical parameters and outcomes in AECOPD patients with failed NIPPV and their conversion to invasive positive pressure ventilation (IPPV).

\section{Methods}

This prospective observational study was conducted in the pulmonology unit of a tertiary care hospital in Pakistan. AECOPD patients with ARF who were candidates of NIPPV were included after securing informed consent. Their demographic characteristics, clinical parameters, and in-hospital outcomes were recorded on a semi-structured proforma. For statistical analysis, SPSS software version 22.0 for Windows (IBM, Armonk, NY) was used.

\section{Results}

With 24 hours of NIPPV, 73 (70.2\%) patients improved and the remaining 31 (29.8\%) were shifted to IPPV. Patients in the IPPV group had higher systolic blood pressure (BP) $[133.8 \mathrm{mmHg}( \pm 21.2) \mathrm{vs.} 121.1 \mathrm{mmHg}$ $( \pm 8.3)$; probability value $(\mathrm{p}):<0.000]$ and lower diastolic BP $[68.7 \mathrm{mmHg}( \pm 13.4)$ vs. $76.2 \mathrm{mmHg}( \pm 10.8)$; p: 0.003]. Their $\mathrm{pH}$ was more acidic [7.20 $( \pm 0.13)$ vs. $7.42( \pm 0.01)$; p: $<0.000]$, heart rates were high [131.1 $( \pm 10.5)$ vs. $100.2( \pm 7.5)$; p: $<0.000]$, and the percentage of oxygen saturation was low $[90.7( \pm 3.0)$ vs. 93.4 $( \pm 4.5$ ); p: 0.004]. Patients who were managed on NIPPV throughout their hospital stay required respiratory

Received 09/26/2019 Review began 09/27/2019 Review ended 09/29/2019 Published 10/01/2019

\section{() Copyright 2019}

Ansari et al. This is an open access article distributed under the terms of the Creative Commons Attribution License CC-BY 3.0., which permits unrestricted use, distribution, and reproduction in any medium, provided the original author and source are credited. support for fewer days [3.2 ( \pm 1.3$)$ vs. $4.1( \pm 1.8)$; p: 0.005], and their hospital stay was shorter $[3.5( \pm 1.2)$ vs. $5.3( \pm 2.5)$ days; $\mathrm{p}:<0.000]$. Mortality rate in the NIPPV group was significantly lower $(1.4 \%$ vs. $12.9 \%$; : $0.01)$.

\section{Conclusions}

Deranged blood pressure, increased heart rate, acidemia, and a low percentage of oxygen saturation are crucial clinical and biochemical parameters that can predict the success of NIPPV with 24 hours of therapy in patients with AECOPD and secondary ARF. Patients who do not improve with 24 hours of NIPPV therapy usually have poor in-hospital outcomes including mortality.

Categories: Emergency Medicine, Pulmonology

Keywords: acute exacerbation of copd, acute respiratory failure, chronic pulmonary obstructive disease, noninvasive ventilation, intubation, invasive ventilation, mechanical ventilation, predictors of mortality, mortality rate

\section{Introduction}

In cases where the damaged respiratory system fails to exchange enough gases, mechanical ventilation must be provided to the patient. Depending on the clinical and biochemical status of the patient, invasive or noninvasive ventilation may be provided [1]. Noninvasive positive pressure ventilation (NIPPV) is provided through a nasal or a face mask at a controlled rate. Invasive positive pressure ventilation (IPPV) is reserved for critical patients and may require endotracheal intubation. The major advantage of NIPPV is that it allows for ventilation support without interfering with the anatomy of the upper airway; however, the use of intubation becomes mandatory in critically ill patients [2]. 
Chronic obstructive pulmonary disease (COPD) is a major respiratory illness that has a profound impact on public health. World Health Organization (WHO) projects COPD to pose the fifth-highest global disease burden by 2020 [3]. COPD has a $6.2 \%$ prevalence in the Asia-Pacific region; of these, $46 \%$ has at least one incidence of acute exacerbation of CODP (AECOPD), and 19\% of AECOPD cases require hospital admission [4]. AECOPD may be triggered by an infectious etiology or discontinuation of COPD medications or precipitated by congestive heart failure or pulmonary embolism. The triggers may go unidentified in some cases [5].

Over the past few years, various instances have been documented in the literature showing favorable outcomes of utilizing NIPPV therapy in acute respiratory failure (ARF) secondary to AECOPD. These outcomes have been measured in terms of reduced mortality rate, need for emergency endotracheal intubation, duration of hospital stay, and rate of complications $[2,6-8]$. The efficiency of NIPPV therapy in ARF patients secondary to AECOPD has been documented from Pakistan as well [9]. In comparison to IPPV, NIPPV patients had a significantly shorter duration of ventilation, intensive care unit (ICU) stay, and hospital stay. The failure rate of NIPPV was $20 \%$ [9]. In-ICU mortality was significantly lower in the NIPPV group; however, post-ICU in-hospital mortality was comparable between the two groups.

Despite promising outcomes of NIPPV in ARF patients, its utilization is limited to only those patients who are alert, conscious, and cooperative to therapy. AECOPD patients with severe respiratory distress may be delirious or irritated and may have a Glasgow Coma Scale (GCS) score of less than 10. They may be hemodynamically unstable or may have concomitant cardiac arrest necessitating emergency intubation and ventilation [10]. NIPPV cannot be administered as first-line therapy in these patients. Furthermore, patients initially managed on NIPPV may deteriorate and require invasive ventilation during the course of their hospital stay. The rate of NIPPV failure has been reported to be $13-53 \%$ in the literature [9,11-13].

Some studies have compared the clinical and biochemical parameters and outcomes in patients with ARF secondary to AECOPD managed via invasive and noninvasive ventilation $[2,7,9,10]$. However, few studies have evaluated the patient characteristics and factors leading to the failure of NIPPV in these patients [12]. Hence, this study was conducted to evaluate the frequency of NIPPV failure and assess the clinical and biochemical parameters and outcomes in AECOPD patients with failed NIPPV and subsequent initiation of IPPV.

\section{Materials And Methods}

This prospective observational study was conducted in the pulmonology unit of a tertiary care hospital in Pakistan. The study was performed from January 1, 2019 to June 30, 2019. We conducted the study after gaining approval from the institutional review board.

Patients included in the study were known cases of COPD and were admitted with acute exacerbation and acute respiratory failure. AECOPD was defined as sudden worsening breathlessness, cough, increased sputum production, and change in sputum color [14]. ARF was categorized as hypercapnia $\left(\mathrm{PaCO}_{2}:>50\right.$ mmHg; pH: <7.30) and hypoxemia $\left(\mathrm{PaO}_{2}:<60 \mathrm{mmHg}\right)$ [15]. Only those patients who were eligible for noninvasive positive pressure ventilation (NIPPV) were included. The patients with any two of the following symptoms were deemed eligible for NIPPV: (i) moderate-to-severe respiratory distress with breathlessness and utilization of accessory muscles along with paradoxical abdominal movement (ii) respiratory rate (RR) of $>25$ breaths/minute (iii) moderate-to-severe acidosis ( $\mathrm{pH}:$ 7.30-7.35) and hypercapnia $\left(\mathrm{PaCO}_{2}: 45-60\right.$ $\mathrm{mmHg}$ ) (iv) moderate-to-severe hypoxemia $\left(\mathrm{PaO}_{2}:<60\right.$ and $\mathrm{PaCO}_{2}:<45 \mathrm{mmHg}$ ). Patients who needed intubation and invasive ventilation immediately, such as those with severe respiratory distress, severe acidemia, respiratory arrest, altered mental status, and those who were hemodynamically or metabolically unstable, were excluded [3]. The clinical and biochemical parameters of all patients were assessed at two hours and 24 hours from the initiation of NIPPV. Those who did not improve and/or deteriorated within/at 24 hours of NIPPV and required immediate invasive ventilation via endotracheal tube were classified into "invasive ventilation group", and those who improved on NIPPV were classified into "noninvasive ventilation group". Patients who deteriorated and required invasive ventilation much after 24 hours of initiation were excluded to reduce bias.

A semi-structured proforma was created to record patient demographic and clinical parameters. Patient age, gender, comorbidity status, duration of COPD, and previous COPD-related hospitalizations were recorded. The clinical parameters included in this study were RR, heart rate (HR), blood pressure (BP), oxygen saturation $\left(\mathrm{SpO}_{2}\right)$, arterial blood pH, and GCS score. Outcomes were assessed in terms of duration of respiratory support, duration of hospital stay, and in-hospital mortality.

For statistical analysis, SPSS software version 22.0 for Windows (IBM, Armonk, NY) was used. Categorical variables were presented as frequencies and percentages. Continuous variables were presented as mean and standard deviation (SD). A chi-squared test was used for categorical variables, and an independent student $\mathrm{t}$ test was used for quantitative variables. A $p$-value of $\leqslant 0.05$ was considered significant. 


\section{Cureus}

\section{Results}

The study included 104 patients who fulfilled the inclusion criteria. There were more males than females (80\% vs. $20 \%$ ). The mean age of the study sample was $39.3( \pm 18.4$ ) years. Most of the patients (52\%) had been suffering from COPD for more than five years. The mean duration of COPD was $4.4( \pm 1.8)$ years. There were some patients with respiratory comorbidities such as tuberculosis (18\%) and asthma (10\%). Cardiometabolic comorbidities were more common. All baseline characteristics are summarized below (Table 1).

\begin{tabular}{ll} 
Baseline characteristics & Number of \\
\hline Gender & \\
Male & $83(79.8 \%)$ \\
Female & $21(20.2 \%)$ \\
Age & \\
Less than 40 years & $23(22.1 \%)$ \\
$40-60$ years & $42(40.4 \%)$ \\
Above 60 years & $39(37.5 \%)$ \\
Duration of COPD & \\
Less than 2 years & $11(10.5 \%)$ \\
$2-5$ years & $39(37.5 \%)$ \\
More than 5 years & $54(51.9 \%)$ \\
Previous hospitalization for AECOPD & \\
Never & $29(27.8 \%)$ \\
Once & $62(59.6 \%)$ \\
More than once & $13(12.5 \%)$ \\
Co morbidity status & \\
Tuberculosis & $11(10.5 \%)$ \\
Asthma & $08(7.6 \%)$ \\
Other chronic respiratory diseases & $28(26.9 \%)$ \\
Cardiovascular disease & $38(36.5 \%)$ \\
Metabolic disease & $19(18.3 \%)$ \\
\hline
\end{tabular}

TABLE 1: Baseline characteristics of the patients at the time of admission $(n=104)$

${ }^{\star}$ Mean ( \pm standard deviation): 39.3 years $( \pm 18.4)$

COPD: chronic obstructive pulmonary disease; AECOPD; acute exacerbation of chronic obstructive pulmonary disease

The clinical characteristics of the patients at two hours of NIPPV are summarized below (Table 2). 


\section{Cureus}

Clinical Parameters

Systolic blood pressure, $\mathrm{mmHg}$

Diastolic blood pressure, $\mathrm{mmHg}$

Respiratory rate per minute

Glasgow Coma Scale score

Arterial $\mathrm{pH}$

$\mathrm{SpO} 2 \%$

Heart rate per minute
Mean ( \pm Standard Deviation)

$134.5( \pm 19.7)$

$70.3( \pm 20.5)$

$25.5( \pm 8.5)$

$12( \pm 3)$

$7.21( \pm 0.11)$

$84.6( \pm 8.2)$

$123.2( \pm 13.6)$

TABLE 2: Clinical parameters when assessed after two hours of initiation of treatment $(n=104)$

$\mathrm{SpO}_{2}$ : peripheral capillary oxygen saturation

The patients were again assessed at 24 hours of NIPPV therapy. At this stage, patients who had improved clinically as well as biochemically were separated from those who either had not improved or deteriorated. Seventy three (70.2\%) patients improved and the remaining 31 (29.8\%) were shifted to invasive ventilation. Patients in the invasive ventilation group had higher systolic BP [33.8 $( \pm 21.2)$ vs. $121.1( \pm 8.3) \mathrm{mmHg}$; p: $<0.000]$ and lower diastolic BP [68.7 $( \pm 13.4)$ vs. $76.2( \pm 10.8) \mathrm{mmHg}$; p: 0.003); their pH was more acidic [7.20 $( \pm 0.13)$ vs. $7.42( \pm 0.01)$; p:<0.000]; heart rates were higher $[131.1( \pm 10.5)$ vs. $100.2( \pm 7.5) ; \mathrm{p}:<0.000]$; and oxygen saturation percentage was lower $[90.7( \pm 3.0)$ vs. $93.4( \pm 4.5)$; p: 0.004$)$. GCS score was not considered a valid parameter for intubated and ventilated patients as they were sedated. RR was not deemed a valid parameter for intubated and ventilated patients as it was determined by the ventilator parameters and not by any effort of the patients. All other parameters are compared below (Table 3).

\begin{tabular}{|c|c|c|c|}
\hline Clinical parameters & Noninvasive ventilation group $(n=73)$ & Invasive ventilation group $(\mathrm{n}=\mathbf{3 1}$ ) & Probability value \\
\hline Systolic blood pressure, $\mathrm{mmHg}$ & $121.1( \pm 8.3)^{\star}$ & $133.8( \pm 21.2)^{*}$ & $<0.000$ \\
\hline Diastolic blood pressure, $\mathrm{mmHg}$ & $76.2( \pm 10.8)^{\star}$ & $68.7( \pm 13.4)^{\star}$ & 0.003 \\
\hline Arterial $\mathrm{pH}$ & $7.42( \pm 0.01)^{\star}$ & $7.20( \pm 0.13)^{\star}$ & $<0.000$ \\
\hline Heart rate per minute & $100.2( \pm 7.5)^{\star}$ & $131.1( \pm 10.5)^{\star}$ & $<0.000$ \\
\hline $\mathrm{SpO}_{2}, \%$ & $93.4( \pm 4.5)^{\star}$ & $90.7( \pm 3.0)^{\star}$ & 0.004 \\
\hline
\end{tabular}

TABLE 3: Clinical parameters at 24 hours in patients improved with noninvasive positive pressure ventilation and patients shifted to invasive ventilation $(n=104)$

*standard deviation

$\mathrm{SpO}_{2}$ : peripheral capillary oxygen saturation

Outcomes in patients who recovered with NIPPV only were compared with those who required intubation and ventilation on three parameters. Patients who improved on NIPPV required respiratory support for a mean duration of $3.2( \pm 1.3)$ days as compared to $4.1( \pm 1.8)$ days in patients who were eventually intubated (p: 0.005). Similarly, the duration of hospital stay was longer for intubated and ventilated patients as compared to those who improved on NIPPV only [5.3 $( \pm 2.5)$ vs. $3.5( \pm 1.2)$ days; p: $<0.000]$. There was only one (1.4\%) death reported in the NIPPV group as compared to $4(12.9 \%)$ in invasive ventilation group (p: 0.01). All outcomes are summarized below (Table 4). 
in some patients, its failure is inevitable. Failure of NIPPV and subsequent immediate intubation could be predicted by unimproved BP, HR, oxygen saturation, and arterial $\mathrm{pH}$ at 24 hours from the initiation of NIPPV therapy. Patients who did not improve with 24 hours of NIPPV therapy had poor in-hospital outcomes, including death. Invasive ventilation should be considered in patients who do not respond to noninvasive ventilation even after 24 hours. There is a pressing need to conduct randomized controlled trials with a more robust methodology to establish the authenticity of clinical and biochemical parameters at 24 hours of NIPPV in predicting its failure and subsequent immediate intubation.

\section{Additional Information \\ Disclosures}

Human subjects: Consent was obtained by all participants in this study. Liaquat University of Medical and Health Sciences issued approval 34/EC/O/18. Animal subjects: All authors have confirmed that this study did not involve animal subjects or tissue. Conflicts of interest: In compliance with the ICMJE uniform disclosure form, all authors declare the following: Payment/services info: All authors have declared that no financial support was received from any organization for the submitted work. Financial relationships: All authors have declared that they have no financial relationships at present or within the previous three years with any organizations that might have an interest in the submitted work. Other relationships: All authors have declared that there are no other relationships or activities that could appear to have influenced the submitted work.

\section{References}

1. Kasper D, Fauci A, Hauser S, Longo D, Jameson J, Loscalzo J: Harrison's principles of internal medicine, 19th ed. McGraw-Hill Education, Philadelphia; 2015.

2. Maleh VA, Monadi M, Heidari B, Maleh PA, Bijani A: Efficiency and outcome of non-invasive versus invasive positive pressure ventilation therapy in respiratory failure due to chronic obstructive pulmonary disease. Caspian J Intern Med. 2016, 7:99-104.

3. Pauwels RA, Buist AS, Calverley PM, Jenkins CR, Hurd SS, GOLD Scientific Committee: Global strategy for the diagnosis, management, and prevention of chronic obstructive pulmonary disease: NHLBI/WHO Global Initiative for Chronic Obstructive Lung Disease (GOLD) workshop summary. Am J Respir Crit Care Med. 2001, 163:1256-76. 10.1164/ajrccm.163.5.2101039

4. Lim S, Lam DC, Muttalif AR, et al.: Impact of chronic obstructive pulmonary disease (COPD) in the AsiaPacific region: the EPIC Asia population-based survey. Asia Pac Fam Med. 2015, 14:4. 10.1186/s12930-0150020-9

5. Ko FW, Chan KP, Hui DS, Goddard JR, Shaw JG, Reid DW, Yang IA: Acute exacerbation of COPD . Respirology. 2016, 21:1152-65. 10.1111/resp.12780

6. Osadnik CR, Tee VS, Carson-Chahhoud KV, Picot J, Wedzicha JA, Smith BJ: Non-invasive ventilation for the management of acute hypercapnic respiratory failure due to exacerbation of chronic obstructive pulmonary disease. Cochrane Database Syst Rev. 2017, CD004104. Accessed: October 1, 2019 : 10.1002/14651858.CD004104.pub4

7. Meeder AM, Tjan DH, van Zanten AR: Noninvasive and invasive positive pressure ventilation for acute respiratory failure in critically ill patients: a comparative cohort study. J Thorac Dis. 2016, 8:813-25. 10.21037/jtd.2016.03.21

8. Bhattacharyya D: Noninvasive ventilation in acute respiratory failure: experience from a tertiary care hospital in India. Am J Respir Crit Care Med. 2017, 195:A5852.

9. Devi P, Raja R, Kumar R, Shah A, Ansari SI, Kumar B: Invasive versus non-invasive positive pressure ventilation in chronic obstructive pulmonary disease complicated by acute respiratory failure. Cureus. 2019, 11:Accessed: October 1, 2019: 10.7759/cureus.5418

10. Lindenauer PK, Stefan MS, Shieh MS, Pekow PS, Rothberg MB, Hill NS: Outcomes associated with invasive and noninvasive ventilation among patients hospitalized with exacerbations of chronic obstructive pulmonary disease. JAMA Intern Med. 2014, 174:1982-93. 10.1001/jamainternmed.2014.5430

11. Raju BM, Jotkar S, Prathyusha M, Goswami S, Dube M, Singh A: Effectiveness of non-invasive positive pressure ventilation for acute exacerbation of chronic obstructive pulmonary disease. Int J Clin Trials. 2018, 5:102-6. 10.18203/2349-3259.ijct20181740

12. Kumar A, Kumar A, Rai K, Ghazal S, Rizvi N, Kumar S, Notani S: Factors leading to poor outcome of noninvasive positive pressure ventilation in acute exacerbation of chronic obstructive pulmonary disease. J Acute Dis. 2015, 4:44-47. 10.1016/S2221-6189(14)60081-0

13. Mosier JM, Sakles JC, Whitmore SP, et al.: Failed noninvasive positive-pressure ventilation is associated with an increased risk of intubation-related complications. Ann Intensive Care. 2015, 5:4. 10.1186/s13613015-0044-1

14. Crisafulli E, Barbeta E, Ielpo A, Torres A: Management of severe acute exacerbations of COPD: an updated narrative review. Multidiscip Respir Med. 2018, 13:36. 10.1186/s40248-018-0149-0

15. Shebl E, Burns B: Respiratory Failure. StatPearls Publishing LLC, Florida; 2019.

16. Schnell D, Timsit JF, Darmon M, et al.: Noninvasive mechanical ventilation in acute respiratory failure: trends in use and outcomes. Intensive Care Med. 2014, 40:582-91. 10.1007/s00134-014-3222-y

17. Carrillo A, Gonzalez-Diaz G, Ferrer M, et al.: Non-invasive ventilation in community-acquired pneumonia and severe acute respiratory failure. Intensive Care Med. 2012, 38:458-66. 10.1007/s00134-012-2475-6

18. Aziz AO, El Bary IM, Fattah MT, Magdy MA, Osman AM: Effectiveness and safety of noninvasive positivepressure ventilation in hypercapnia respiratory failure secondary to acute exacerbation of chronic obstructive pulmonary disease. Egypt J Bronchol. 2017, 11:215-23. 10.4103/1687-8426.211398

19. Sprooten RT, Janssen MT, Braeken DC, Rohde GG: Response to non-invasive ventilation as a predictor for 


\section{Cureus}

mortality in patients with acute respiratory failure due to acute exacerbation of COPD. Eur Respir J. 2017, 50:2164. 10.1183/1393003.congress-2017.PA2164

20. Fan L, Zhao Q, Liu Y, Zhou L, Duan J: Semiquantitative cough strength score and associated outcomes in noninvasive positive pressure ventilation patients with acute exacerbation of chronic obstructive pulmonary disease. Respir Med. 2014, 108:1801-7. 10.1016/j.rmed.2014.10.001

21. Soliman MA, El-Shazly MI, Soliman YM, Mostafa AI: Effectiveness of non invasive positive pressure ventilation in chronic obstructive pulmonary disease patients. Egypt J Chest Dis Tuberc. 2014, 63:309-12. 10.1016/j.ejcdt.2013.12.018 